\title{
Regioselective glucosidation of trans-resveratrol in Escherichia coli expressing glucosyltransferase from Phytolacca americana
}

\author{
Shin-ichi Ozaki • Hiroya Imai · Tomoya Iwakiri • \\ Takehiro Sato - Kei Shimoda · Toru Nakayama • \\ Hiroki Hamada
}

Received: 12 July 2011/Accepted: 17 October 2011/Published online: 3 November 2011

(C) The Author(s) 2011. This article is published with open access at Springerlink.com

\begin{abstract}
A glucosyltransferase (GT) of Phytolacca americana (PaGT3) was expressed in Escherichia coli and purified for the synthesis of two $O$ - $\beta$-glucoside products of trans-resveratrol. The reaction was moderately regioselective with a ratio of $4^{\prime}-O$ - $\beta$-glucoside: 3-O- $\beta$-glucoside at 10:3. We used not only the purified enzyme but also the $E$. coli cells containing the PaGT3 gene for the synthesis of glycoconjugates. E. coli cell cultures also have other advantages, such as a shorter incubation time compared with cultured plant cells, no need for the addition of exogenous glucosyl donor compounds such as UDP-glucose, and almost complete conversion of the aglycone to the glucoside products.
\end{abstract}

S. Ozaki · T. Iwakiri · T. Sato

Department of Biological Sciences, Faculty of

Agriculture, Yamaguchi University, Yoshida,

Yamaguchi 753-8511, Japan

H. Imai · H. Hamada $(\bowtie)$

Department of Life Sciences, Faculty of Science,

Okayama University of Sciences, 1-1 Ridai-cho, Kita-ku,

Okayama 700-0005, Japan

e-mail: hamada@dls.ous.ac.jp

K. Shimoda

Department of Pharmacology and Therapeutics,

Faculty of Medicine, Oita University, Hasama-machi,

Oita 879-5593, Japan

T. Nakayama

Department of Biomolecular Engineering,

Graduate School of Engineering, Tohoku University,

Sendai, Miyagi 980-8579, Japan
Furthermore, a homology model of PaGT3 and mutagenesis studies suggested that His-20 would be a catalytically important residue.

Keywords Glucosyltransferase - Glycoconjugates · Phytolacca americana $\cdot$ Resveratrol

\section{Introduction}

Resveratrol, which is a naturally occurring hydroxystilbene, has a broad range of biological activities and can be used in treatments for the metabolic syndrome (Cherniack 2011; Xianfeng-Huang and Zhu 2011). It can lower the weight, blood pressure, glucose, and insulin resistance in rodents, and a human trial with it is currently underway. However, the water-insolubility of resveratrol limits its pharmacological exploitation but its water-soluble derivatives, resveratrol 3-O- $\beta$-Dglucoside and resveratrol $4^{\prime}-O$ - $\beta$-D-glucoside, show pharmaceutical properties such as cancer prevention (Ingram et al. 1998), anti-oxidant activity (Tikkanen et al. 1998) and estrogenic activity (Gehm et al. 1997). The glucosidation of trans-resveratrol is therefore of considerable importance the further exploitation of trans-resveratrol.

Cultured plant cells can be used to convert organic molecules to more useful compounds (Suga and Hirata 1990) by carrying out hydrolysis, oxidation, reduction, esterification, isomerization, and glycosylation 
reactions (Ishihara et al. 2003; Suga and Hirata 1990). Glycosylation of bioactive compounds can enhance water solubility, physicochemical stability, intestinal absorption, and biological half-life (Vogt and Jones 2000). Many secondary metabolites accumulate in the form of glycosides in plants suggesting that suspension of such cells would contain glucosyltransferases (GTs), which catalyze the conjugation of an aglycone and a glucosyl donor molecule (Furuya et al. 1989).

We previously reported that the plant cell cultures from Phytolacca americana $(\mathrm{Pa})$ glycosylated exogenous compounds (Noguchi et al. 2009). Three glucosyltransferase cDNAs ( $P a \mathrm{GT} 1-3)$ were isolated from $P$. americana. In this study, we report that $P a \mathrm{GT} 3$, which accepts a broad range of substrates, could catalyze regio- and stereo-specific glucosidation of resveratrol using a purified enzyme as well as the recombinant $E$. coli cells bearing the $P a \mathrm{GT} 3$ gene. Furthermore, we constructed the $P a \mathrm{GT} 3$ model structure and performed mutagenesis studies in order to examine amino acid residues involved in the substrate recognition and the catalytic process.

\section{Methods and materials}

\section{General}

All chemicals were purchased from Wako, Nakalai, and Sigma-Aldrich, and enzymes for mutagenesis were obtained from Toyobo. HRFAB-MS spectra were measured on a JEOL MS station JMS-700 spectrometer. The ${ }^{1} \mathrm{H}$-and ${ }^{13} \mathrm{C}$-NMR spectra were recorded using Varian XL-400 spectrometer.

Glucosidation of trans-resveratrol with cultured plant cells

Callus tissues from Phytolacca americana L. were prepared (see Hamada et al. 2003). Callus tissue (20 g) was cultured under light for 4 weeks, transferred to an Erlenmeyer flask (300 ml) containing $100 \mathrm{ml}$ Murashige and Skoog (MS) liquid medium, and cultured with continuous shaking at $25^{\circ} \mathrm{C}$. Ten mg of trans-resveratrol was added to the flask and the cells were incubated for an additional 3 days at $25^{\circ} \mathrm{C}$. Following incubation, the cells were isolated by filtration, and extracted with methanol $(200 \mathrm{ml})$ for $24 \mathrm{~h}$. The methanol fraction was concentrated and partitioned between water $(100 \mathrm{ml})$ and ethyl acetate $(300 \mathrm{ml})$; the ethyl acetate fraction was analyzed by HPLC. The substrate and glucosylated products were separated using YMC-Pack R\&D ODS column and acetonitrile/water (15:85, v/v) at $1 \mathrm{ml} / \mathrm{min}$, with detection at $280 \mathrm{~nm}$. Product yields were calculated based on the peak area from the HPLC profile using the calibration curves prepared by similar HPLC analyses of known glycosides.

Glucosidation of trans-resveratrol by purified PaGT3 enzyme

$P a$ GT3 cDNA was cloned into pQE30 containing 6XHis tag at the $N$-terminus, and the resulting pQE30$P a \mathrm{GT} 3$ plasmid was transformed into E. coli M15 cells. The transformants were cultured with continuous shaking at $30^{\circ} \mathrm{C}$ in the Luria- Bertani (LB) broth containing $50 \mu \mathrm{g}$ ampicillin/ml. After $16 \mathrm{~h}, 20 \mathrm{ml}$ culture was transferred to 21 fresh LB broth, and cultured with shaking at $30^{\circ} \mathrm{C}$; at $\mathrm{OD}_{600}=1$, IPTG was added to $0.1 \mathrm{mM}$, followed by incubation at $30^{\circ} \mathrm{C}$ for an additional $16 \mathrm{~h}$. To purify the PaGT3 enzyme, the harvested cells were collected by centrifugation for $10 \mathrm{~min} 5,000 \times g$ resuspended in buffer $\mathrm{H}(15 \mathrm{mM}$ potassium phosphate, $1 \mathrm{mM}$ EDTA, $2 \mathrm{mM}$ 2-mercapotoethanol). Cells were lysed by sonication, and cellular debris were removed by centrifugation for $15 \min 5,000 \times g$, and the supernatant was applied to a His-accept column equilibrated with buffer $\mathrm{H}$. The column was washed with buffer $\mathrm{H}$ to remove impurities, and the bound PaGT3 enzyme was eluted with buffer H supplemented with $200 \mathrm{mM}$ imidazole. The purified $P a \mathrm{GT} 3$ enzyme solution was dialyzed for $16 \mathrm{~h}$ at $4^{\circ} \mathrm{C}$ with $50 \mathrm{mM}$ potassium phosphate buffer (pH 7.2).

The His-20 PaGT3 mutants were constructed from pQE30-PaGT3 by polymerase chain reaction (PCR) using primers $5^{\prime}$-GCCCATGGGGCCATGATCCC G- $3^{\prime}$ and $5^{\prime}$ - CGGGATCATGGCCCCATGGGC- $3^{\prime}$ for H20A $P a G T 3$, and 5'-GCCCATGGGGATATGA TCCCG- $3^{\prime}$ and $5^{\prime}$ - CGGGATCATATCCCCATGG GC- $3^{\prime}$ for H20D PaGT3. The plasmids with His-20 mutations were transformed into $E$. coli M15 cells and characterized by sequencing.

Glucosidation reactions were performed at $30^{\circ} \mathrm{C}$ for $60 \mathrm{~min}$ in $0.5 \mathrm{ml} 50 \mathrm{mM}$ potassium phosphate buffer (pH 7.2) supplemented with $50 \mu \mathrm{M}$ trans-resveratrol, $100 \mu \mathrm{M}$ UDP-glucose, and $1 \mu \mathrm{M}$ PaGT3. The 
substrates and glucosylated products were separated using Insertsil ODS-3 column, and the standard gradient program, which was as follows: the ratio of water (A) to acetonitrile (B) was initially 80:20 at a time $0-15 \mathrm{~min}$, then the A:B ratio was linearly increased from 80:20 (v/v) at $\mathrm{t}=15 \mathrm{~min}$ to $20: 80$ $(\mathrm{v} / \mathrm{v})$ at $\mathrm{t}=40 \mathrm{~min}$ followed by a final wash with $100 \%$ acetonitrile. The UV-visible detector was set at $280 \mathrm{~nm}$.

Glucosidation of trans-resveratrol by the $E$. coli cell cultures

E. coli M15 cells containing pQE30-PaGT3 were cultured as described above in $10 \mathrm{ml} \mathrm{LB}$ medium containing $0.1 \mathrm{mg}$ tans-resveratrol $/ 1$ and $50 \mu \mathrm{g} / \mathrm{ml}$ ampicillin. After induction for $16 \mathrm{~h}$ with $0.1 \mathrm{mM}$ IPTG, the cells and the medium were separated, and the products were extracted from the medium with $2 \times 10 \mathrm{ml}$ ethyl acetate. Ethyl acetate was evaporated using a rotary evaporator and the residue was analyzed by HPLC. Alternatively, the medium was applied to Diaion HP-20 (1 g), washed with water, and eluted with methanol. The methanol solution was analyzed by HPLC using the standard gradient program.

\section{Analysis}

The ${ }^{1} \mathrm{H}$-and ${ }^{13} \mathrm{C}$-NMR spectra were recorded in $\mathrm{CD}_{3} \mathrm{OD}$. The chemical shifts were expressed in $\delta$ (ppm) referring to TMS. ${ }^{1} \mathrm{H}-\mathrm{NMR}$ spectra of transresveratrol 3-O- $\beta$-glucoside and $4^{\prime}-O-\beta$-glucoside were essentially identical to those of authentic spectra (Weis et al. 2006). The $\beta$-configuration was confirmed by anomeric proton signals at $\delta 4.80(1 \mathrm{H}, \mathrm{d}, J=7.6 \mathrm{~Hz})$ and $\delta 4.88(1 \mathrm{H}, \mathrm{d}, J=7.6 \mathrm{~Hz})$ for trans-resveratrol 3-O- $\beta$-glucoside and $44^{\prime}-O-\beta$-glucoside, respectively. ${ }^{13} \mathrm{C}$-NMR of trans-resveratrol 3-O- $\beta$-glucoside: $\delta 139.3$ (C-1), 107.1 (C-2), 158.0 (C-3), 102.7 (C-4), 158.8 (C-5), 104.7 (C-6), 125.1 (C-7), $128.5(\mathrm{C}-8), 129.9$ $\left(\mathrm{C}-1^{\prime}\right), 128.0\left(\mathrm{C}-2^{\prime}\right), 115.5\left(\mathrm{C}-3^{\prime}\right), 157.2\left(\mathrm{C}-4^{\prime}\right), 115.5$ $\left(\mathrm{C}-5^{\prime}\right), 127.8\left(\mathrm{C}-6^{\prime}\right), 100.6\left(\mathrm{C}-1^{\prime \prime}\right), 73.3\left(\mathrm{C}-2^{\prime \prime}\right), 76.7$ $\left(\mathrm{C}-3^{\prime \prime}\right), 69.8\left(\mathrm{C}-4^{\prime \prime}\right), 77.1\left(\mathrm{C}-5^{\prime \prime}\right), 60.8\left(\mathrm{C}-6^{\prime \prime}\right) .{ }^{13} \mathrm{C}$ NMR of trans-resveratrol $4^{\prime}-O-\beta$-glucoside: $\delta 138.3(\mathrm{C}-1)$, 104.4 (C-2), 158.4 (C-3), 102.0 (C-4), 158.2 (C-5), 104.4 (C-6), 127.1 (C-7), 127.5(C-8), $130.7\left(\mathrm{C}-1^{\prime}\right)$, $127.3\left(\mathrm{C}-2^{\prime}\right), 116.3\left(\mathrm{C}-3^{\prime}\right), 156.8\left(\mathrm{C}-4^{\prime}\right), 116.3\left(\mathrm{C}-5^{\prime}\right)$, $127.3\left(\mathrm{C}-6^{\prime}\right), 100.2\left(\mathrm{C}-1^{\prime \prime}\right), 73.2\left(\mathrm{C}-2^{\prime \prime}\right), 76.6\left(\mathrm{C}-3^{\prime \prime}\right)$, $69.7\left(\mathrm{C}-4^{\prime \prime}\right), 77.0\left(\mathrm{C}-5^{\prime \prime}\right), 60.7\left(\mathrm{C}-6^{\prime \prime}\right)$.
Construction of the homology modeling of $\mathrm{PaGT3}$

The homology model of $P a \mathrm{GT} 3$ was constructed using the Swiss-model (http://swissmodel.expasy.org) with the crystal structure of GT from Vitis vinifera (pdb code: 2C1Z) as a template (Offen et al. 2006). The model and the template were compared using the Swisspdb viewer (http://spdbv.vital-it.ch/) and PyMol (http:// www.pymol.org/) (Kiefer et al. 2009; Kopp and Schwede 2006; Peitsch 1995).

\section{Results and discussion}

The production of trans-resveratrol 3-O- $\beta$ glucoside and $4^{\prime}-O-\beta$-glucoside by $P a \mathrm{GT} 3$

Cell suspension cultures of $P$. americana could glucosylate trans-resveratrol to synthesize 3-O- $\beta$-glucoside and $4^{\prime}-O-\beta$-glucoside (Scheme 1 ). In this system, the addition of UDP-glucose was not required because glucosyl donor molecules were regenerated. Conjugation products were extracted from the cells and purified by reverse phase HPLC (Fig. 1a). Under the reverse phase HPLC conditions, $4^{\prime}-O-\beta$-glucoside eluted faster than 3-O- $\beta$-glucoside, as previously reported (Weis et al. 2006). The HRFABMS spectra of these isolated glucosides showed a pseudomolecular ion $[\mathrm{M}+\mathrm{H}]^{+}$peak at $m / z$ 391, suggesting a molecular formula of $\mathrm{C}_{20} \mathrm{O}_{8} \mathrm{H}_{22}$ (calculated for 390). The comparison of NMR spectra with those of the known monoglucoside standards confirmed the synthesis of trans-resveratrol 3-O- $\beta$ glucoside and $4^{\prime}-O-\beta$-glucoside in the culture medium. Interestingly, the product distribution was considerably altered by the addition of 2,4-dichlorophenoxyacetic acid as a synthetic auxin to the culture medium (Fig. 1b). The synthesis of $4^{\prime}-O$ - $\beta$-glucoside was notably enhanced following incubation with the plant hormone.

To investigate the changes in regiospecificity, we heterologously expressed $P a \mathrm{GT} 3$ in E. coli and purified the enzyme to synthesize the glucosides. When transresveratrol was incubated with UDP-glucose in the presence of $\mathrm{Pa \textrm {GT }} 3,4^{\prime}-\mathrm{O}$ - $\beta$-glucoside was obtained as the major product (Fig. 1c). The ratio of peak area for $4^{\prime}-O-\beta$-glucoside to that for $3-O-\beta$-glucoside in the HPLC profile was 10:3. The product distribution was not altered following the addition of 2,4-dichlorophenoxyacetic acid, phenyl acetic acid, or 1-naphthalene acetic acid, indicating that these hormones do not 


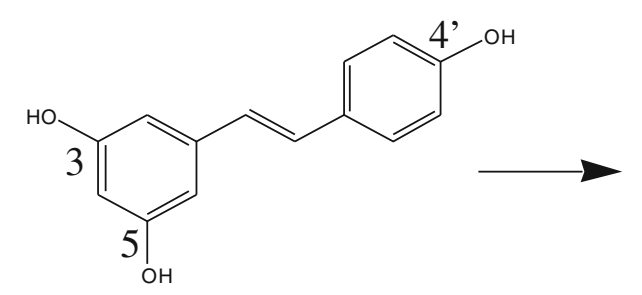

trans-resveratrol<smiles>CO[B]OC(C)=O</smiles><smiles>OCC1COCCC(Oc2cc(O)cc(/C=C/c3ccc(O)cc3)c2)C1O</smiles>

3-O- $\beta-$ glucoside

Scheme 1 Glucosidation of trans-resveratrol
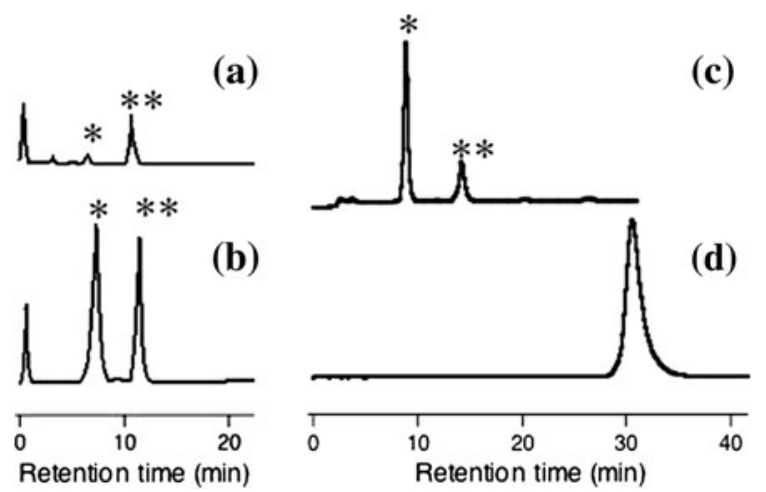

Fig. 1 HPLC profiles of the glucosylated products obtained from incubation with a Phytolacca americana cells in the absence of auxin, b $P$. americana cells in the presence of 2,4dichlorophenoxyacetic acid, and $\mathbf{c}$ the purified $P a \mathrm{GT} 3$ enzyme. $*$ and $* *$ indicate trans-resveratrol $4^{\prime}-O$ - $\beta$-glucoside and transresveratrol 3-O- $\beta$-glucoside, respectively. d The starting material trans-resveratrol was eluted at $31 \mathrm{~min}$

interact directly with the purified $P a \mathrm{GT} 3$ enzyme. From these observations, we believe that 2,4-dichlorophenoxyacetic acid may induce the expression of $P a \mathrm{GT} 3$ in the cultured cells, resulting in enhanced $4^{\prime}-O$ - $\beta$-glucoside production. The expression and purification of $P a \mathrm{GT} 1$ and $P a \mathrm{GT} 2$ are now under way to examine the regiospecificity for the glucosidation reaction catalyzed by these isozymes.

\section{Biotransformation of trans-resveratrol} by $E$. coli cells

The results of this study show that purified PaGT3 catalyzes the glucosidation of trans-resveratrol. Next, we attempted to use $E$. coli cells expressing $P a \mathrm{GT} 3$ gene to promote the glucoside synthesis because E. coli cells grow faster than $P$. americana cells. When $P a$ GT3-expressing E . coli cells were cultured in the presence of trans-resveratrol, glucoside products of trans-resveratrol were detected in the medium of overnight culture. Interestingly, endogenous glucosyl donor molecules were sufficient for the reaction, since the reaction occurred even when UDP-glucose was not added to the medium. The products were extracted from the medium using ethyl acetate and identified by reverse-phase HPLC as 3-O- $\beta$-glucoside and $4^{\prime}-O-\beta-$ glucoside. The glucosidation of trans-resveratrol was almost $100 \%$ using this method, and a peak corresponding to resveratrol, starting material, was not observed in the HPLC profile (Fig. 2). This was a considerable improvement because only $39 \%$ of transresveratrol was glucosylated in $P$. americana cell cultures. Furthermore, the use of $E$. coli cells allowed the incubation time to be shortened from 3 days to 1 . The glucoside products accumulated in the medium and could not be isolated from the cell extracts. Since $P a \mathrm{GT} 3$ is not secreted from the E. coli cells, transresveratrol and its glucoside products may pass through the cell membrane. These results indicate that $P a \mathrm{GT} 3$ expressing $E$. coli cells utilize endogenous UDP-glucose to convert trans-resveratrol completely into the glucosides.

We also found that Diaion HP20 could be used to isolate the glucoside products from the medium instead of extracting the glucosides with ethyl acetate. 


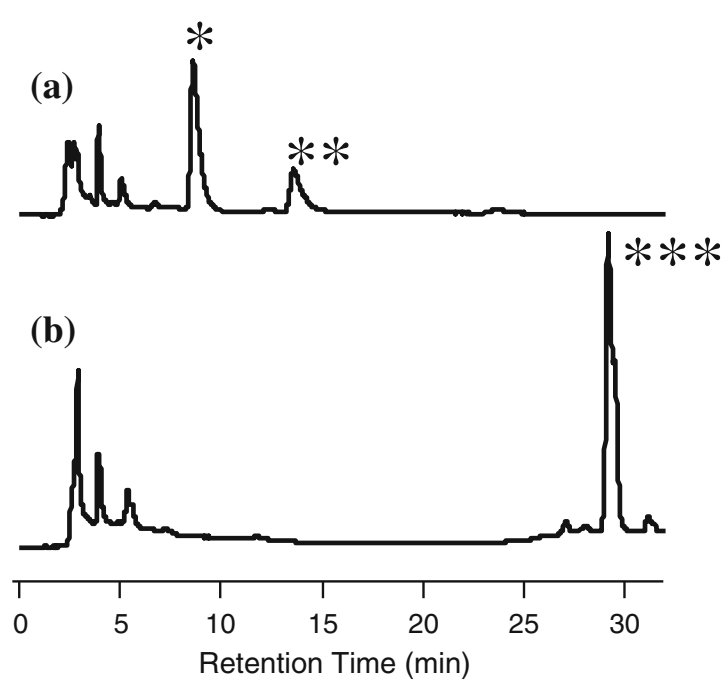

Fig. 2 HPLC profiles of glucosylated products obtained from the incubation of $E$. coli expressing a wild type $P a \mathrm{GT} 3$ gene and b H20A $P a \mathrm{GT} 3$ gene. HPLC profile b was similar to that obtained in the incubation with $E$. coli expressing H20D PaGT3 gene. *, **, and $* * *$ indicate trans-resveratrol $4^{\prime}-O-\beta$-glucoside, trans-resveratrol 3-O- $\beta$-glucoside, and trans-resveratrol, respectively

The aromatic moiety of trans-resveratrol glucosides appeared to interact with the non-polar hydrophobic surface of HP20 resin by van der Waals force, and the glucoside products bound on the resin were eluted with methanol. The use of HP20 is convenient for the isolation of glucosylated products from the medium obtained by a large scale incubation.

(a)

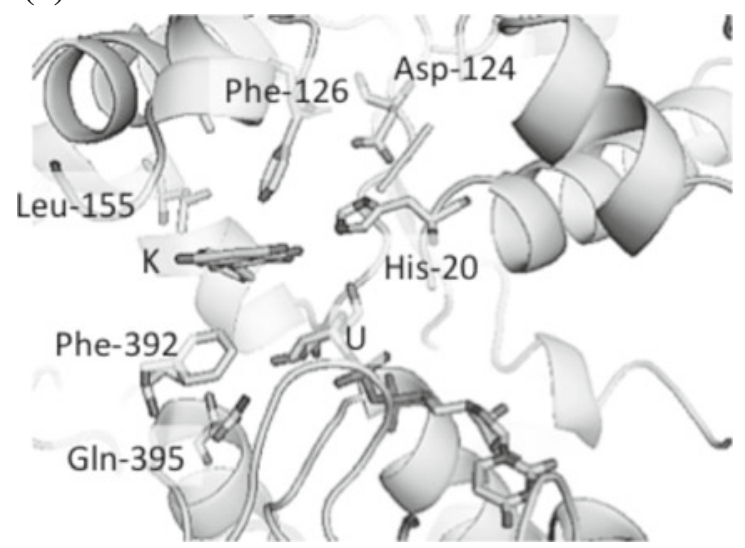

Fig. 3 a The active site of $P a \mathrm{GT} 3$ model. The predicted $P a \mathrm{GT} 3$ structure was superimposed upon the crystal structure of $V v \mathrm{GT}$ bearing UDP-2-deoxy-2-fluoro glucose (nontransferable donor) and kaempferol (acceptor). UDP-2-deoxy-2-fluoro glucose $(U)$, kaempferol $(K)$, and some selected active site residues of
Molecular modeling and mutagenesis studies

The X-ray crystal structure of PaGT3 may yield important insights into the reaction mechanism; however, the structure of $P a \mathrm{GT} 3$ has not yet been determined. Therefore, we constructed a structural model of PaGT3 using the crystal structure of GT from $V$. vinifera $(V v \mathrm{GT})$ as a template (Offen et al. 2006). The predicted $P a \mathrm{GT} 3$ structure was then superimposed upon the crystal structure of $V v G T$ bearing UDP-2-deoxy-2-fluoro glucose (a nontransferable donor molecule) and kaempferol (a glucose acceptor molecule) at the active site for comparison (Fig. 3a). A putative model structure of $P a \mathrm{GT} 3$ implies that Gln-395 may play an important role in appropriate positioning of UDP-glucose, a glucose donor molecule. trans-Resveratrol, a glucose acceptor molecule, may bind $P a \mathrm{GT} 3$ in the hydrophobic pocket surrounded by Phe-126, Leu-155, and Phe-392. A histidine residue conserved in the active site of GTs normally accept a proton from the hydroxy group of an acceptor molecule and promote the nucleophilic attack on C1 of UDP-glucose (Fig. 3b) (Lairson and Withers 2004). The model structure of $P a \mathrm{GT} 3$ clearly suggests that His-20 rather than His-18 is the catalytic residue. Moreover, the hydrogen-bonding interaction between the carboxy side chain of Asp-124 and the $\mathrm{N} \delta$ atom of His-20 might increase the basicity of this imidazole to enhance the nucleophilicity. (b)

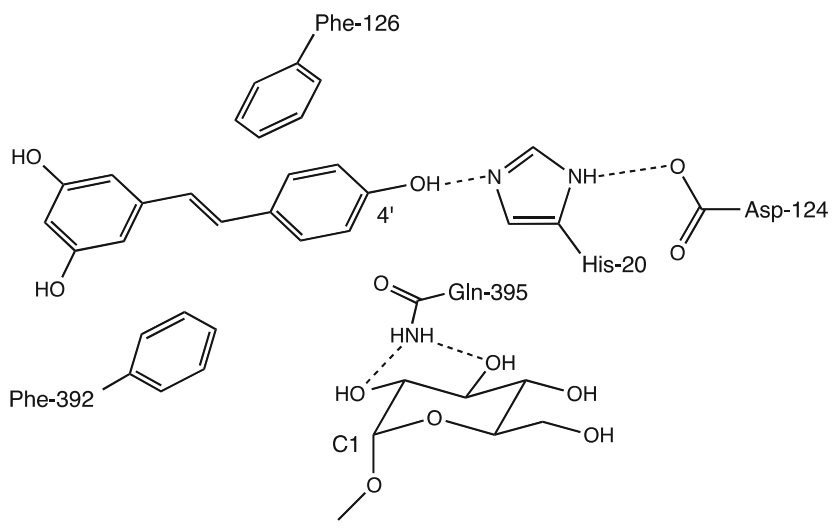

$P a \mathrm{GT} 3$ are shown. b Schematic diagram of active site of $P a \mathrm{GT} 3$ model. The dashed lines indicate hydrogen bonds. A hydrogen bond between His-20 and the 4'-hydroxy group of trans-resveratrol may promote nucleophilic attack on $\mathrm{C} 1$ of UDP-glucose to produce $4^{\prime}-\beta$ - $O$-glucoside 


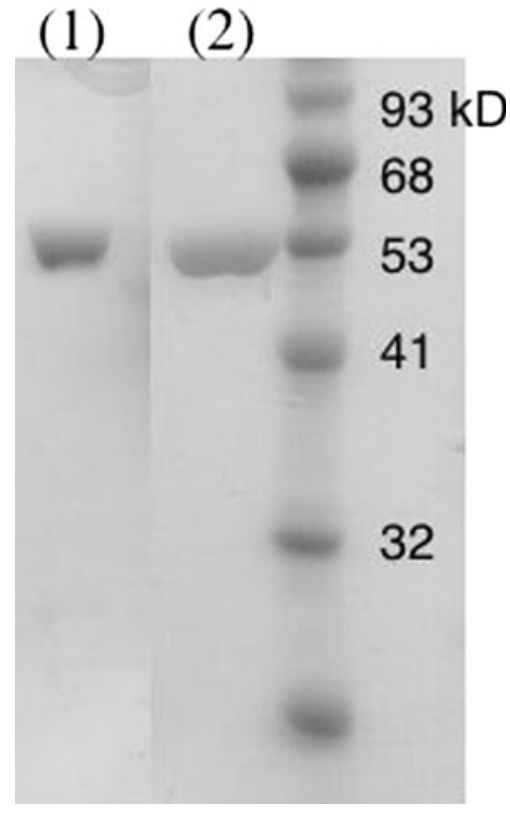

Fig. 4 SDS-PAGE of the purified 1 H20A and 2 H20D PaGT3 enzymes

In order to determine if His-20 is a catalytically important residue, we decided to substitute His-20 with Ala and Asp and measure the GT activity of these mutants. The expression levels of the mutated enzymes were comparable to the wild type enzyme. We could successfully purify the mutant enzymes using nickel-nitrilotriacetic acid affinity columns and analyzed their GT activity (Fig. 4). We were unable to detect glucosidation products in the reaction mixture containing trans-resveratrol (acceptor), UDP-glucose (donor), and the H20A and H20D PaGT3 mutant enzymes. The incubation of $E$. coli cells expressing the H20A and H20D mutant PaGT3 enzymes in the medium containing trans-resveratrol did not produce the glucosides either (Fig. 2). These results provided the experimental evidence that His-20 in the active site was critical for the GT reaction. The mutagenesis of residues interacting with an acceptor molecule might allow us to construct a novel enzyme glucosylating a broad range of biologically active molecules.

\section{Conclusions}

Purified $\mathrm{PaGT} 3$ glucosylates trans-resveratrol to $4^{\prime}-O$ $\beta$-glucoside (a major product) and 3-O- $\beta$-glucoside (a minor product). Based on homology modeling, resveratrol may bind $P a \mathrm{GT} 3$ in a hydrophobic pocket similar to the GT from $V$. vinifera $(V v \mathrm{GT})$. The predicted structure of $P a \mathrm{GT} 3$ indicated that His-20 probably was a catalytically important residue for the nucleophilic attack of the aglycone on the $\mathrm{C} 1$ of UDP-glucose. This was confirmed by mutational analysis because H20A and H20D PaGT3 mutant enzymes lacked GT activity. Furthermore, E. coli expressing the $\mathrm{PaGT3}$ gene was used for the glycoconjugation of trans-resveratrol in the culture medium. The advantages of using $E$. coli cell cultures are a shorter incubation time compared with cultured plant cells, no need for the addition of exogenous glucosyl donor compounds, such as UDP-glucose, and the almost complete conversion of the aglycone to the glucoside products. The use of $E$. coli cell cultures combined with molecular engineering of $P a \mathrm{GT} 3$ may provide a new biocatalyst for the glucosidation of aromatic compounds.

Acknowledgments We thank Regional Innovation Creation R\&D Programs (Japan) for their financial support

Open Access This article is distributed under the terms of the Creative Commons Attribution Noncommercial License which permits any noncommercial use, distribution, and reproduction in any medium, provided the original author(s) and source are credited.

\section{References}

Cherniack EP (2011) Polyphenols: planting the seeds of treatment for the metabolic syndrome. Nutrition 27:617-623

Furuya T, Ushiyama M, Asada Y, Yoshikawa T (1989) Biotransformation of 2-phenylpropionic acid in root culture of Panax ginseng. Phytochemistry 28:483-487

Gehm BD, McAndrews JM, Chien PY, Jameson JL (1997) Resveratrol, a polyphenolic compound found in grapes and wine, is an agonist for the estrogen receptor. Proc Natl Acad Sci USA 94:14138-14143

Hamada H, Ohiwa S, Nishida T, Katsuragi H, Takeda T, Hamada $H$, Nakajima N, Ishihara K, Hamada H, Hirata T, Nakajima N (2003) One-step glucosylation of capsaicinoide by cultured cells of Phytolacca americana. Plant Biotechnol 20:253-255

Ingram D, Sanders K, Kolybaba M, Lopez D (1998) Case-control study of phyto-oestrogens and breast cancer. Lancet 350:990-994

Ishihara K, Hamada H, Hirata T, Nakajima N (2003) Biotransformation using plant cultured cells. J Mol Catal B Enz 23:145-170

Kiefer F, Arnold K, Künzli M, Bordoli L, Schwede T (2009) The SWISS-MODEL repository and associated resources. Nucleic Acids Res 37:D387-D392 
Kopp J, Schwede T (2006) The SWISS-MODEL repository: new features and functionalities. Nucleic Acids Res 34:D315-D318

Lairson LL, Withers SG (2004) Mechanistic analogies amongst carbohydrate modifying enzymes. Chem Commun (Camb, Engl) 20:2243-2248

Noguchi A, Kunikane S, Homma H, Liu W, Sekiya T, Hosoya M, Kwon S, Ohiwa S, Katsuragi H, Nishino T, Takahashi S, Hamada H, Nakayama T (2009) Identification of an inducible glucosyltransferase from Phytolacca americana L. cells that are capable of glucosylating capsaicin. Plant Biotechnol 26:285-292

Offen W, Martinez-Fleites C, Yang M, Kiat-Lim E, Davis BG, Tarling CA, Ford CM, Bowles DJ, Davies GJ (2006) Structure of a flavonoid glucosyltransferase reveals the basis for plant natural product modification. EMBO J 25:1396-1405

Peitsch MC (1995) Protein modeling by E-mail. Biotechnology 13:658-660
Suga T, Hirata T (1990) Biotransformation of exogenous substrates by plant cell cultures. Phytochemistry 29:2393-2406

Tikkanen MJ, Wahala K, Ojala S, Vihma V, Adlercreutz H (1998) Effect of soybean phytoestrogen intake on low density lipoprotein oxidation resistance. Proc Natl Acad Sci USA 95:3106-3110

Vogt T, Jones P (2000) Glycosyltransferases in plant-natural product synthesis: characterization of a super gene family. Trend Plant Sci 5:380-386

Weis M, Lim EK, Bruce N, Bowles D (2006) Regioselective glucosylation of aromatic compounds: screening of a recombinant glycosyltransferase library to identify biocatalysts. Angew Chem Int Ed 45:3534-3538

Xianfeng-Huang X-H, Zhu H-L (2011) Resveratrol and its analogues: promising antitumor agents. Anticancer Agents Med Chem 11:479-490 